\title{
Impact of the COVID-19 Pandemic on Partner Relationships and Sexual and Reproductive Health: Cross-Sectional, Online Survey Study
}

Guanjian $\mathrm{Li}^{1}$, MD; Dongdong Tang ${ }^{1}, \mathrm{MD}$; Bing Song ${ }^{2}$, MD, PhD; Chao Wang ${ }^{2}$, MD; Shen Qunshan², MD; Chuan $\mathrm{Xu}^{2}$, MD; Hao Geng ${ }^{1}, \mathrm{MD}$; Huan $\mathrm{Wu}^{2}, \mathrm{MD}, \mathrm{PhD}$; Xiaojin $\mathrm{He}^{1^{*}}, \mathrm{MD}, \mathrm{PhD}$; Yunxia Cao ${ }^{1 *}, \mathrm{MD}, \mathrm{PhD}$

\footnotetext{
${ }^{1}$ Reproductive Medicine Center, Department of Obstetrics and Gynecology, The First Affiliated Hospital of Anhui Medical University, National Health Commission Key Laboratory of Study on Abnormal Gametes and Reproductive Tract, Hefei, China

${ }^{2}$ Key Laboratory of Population Health Across Life Cycle, Ministry of Education of the People's Republic of China, Anhui Province Key Laboratory of Reproductive Health and Genetics, Hefei, China

* these authors contributed equally
}

\section{Corresponding Author:}

Yunxia Cao, MD, $\mathrm{PhD}$

Reproductive Medicine Center, Department of Obstetrics and Gynecology

The First Affiliated Hospital of Anhui Medical University

National Health Commission Key Laboratory of Study on Abnormal Gametes and Reproductive Tract

81 Meishan Road

Hefei, 230000

China

Phone: 8615395104659

Fax: 86055165161058

Email: caoyunxia6@126.com

\section{Abstract}

Background: In the past few months, the coronavirus disease (COVID-19) pandemic has caused extensive economic and social damage.

Objective: The purpose of this study was to assess the impact of COVID-19-related measures on partner relationships and sexual and reproductive health in China.

Methods: From May 1 to 5, 2020, 3500 young Chinese individuals were recruited through WeChat or Weibo to participate in a survey to obtain information on sexual and reproductive health (eg, sexual desire, frequency of sexual intercourse, sexual satisfaction, etc). The questionnaire also collected demographic data (eg, age, race, education, current financial status, sexual orientation, relationship status, etc).

Results: In total, 967 participants were included in the sexual health analysis. Due to the COVID-19 pandemic and related containment measures, $22 \%$ of participants $(n=212)$ reported a decrease in sexual desire; $41 \%(n=396)$ experienced a decrease in the sexual intercourse frequency; $30 \%(n=291)$ reported an increase in the frequency of masturbation; 20\% ( $n=192)$ reported a decrease in alcohol consumption before or during sexual activities, and $31 \%(\mathrm{n}=298)$ reported a deterioration in partner relationships during the pandemic. The logistic regression analysis indicated that the following influenced partner relationships: accommodations during the pandemic $(P=.046$; odds ratio [OR] $0.59 ; 95 \%$ CI $0.30-0.86)$; exclusive relationship status (yes or no) $(P<.001$; OR 0.44; $95 \%$ CI 0.27-0.73); sexual desire ( $P=.02$; OR 2.01; 95\% CI 1.38-2.97); and sexual satisfaction $(P<.001$; OR 1.92; 95\% CI 1.54-2.50). COVID-19 also caused disruptions in reproductive health services such as prenatal and postnatal care, childbirth and abortion services, contraception availability, and the management of sexually transmitted infections.

Conclusions: Our results show that many young people have wide-ranging issues affecting their sexual and reproductive health due to the COVID-19 pandemic and related containment measures. Strategies and guidelines are needed to safeguard the sexual and reproductive health of young people during this pandemic.

(J Med Internet Res 2020;22(8):e20961) doi: 10.2196/20961 


\section{KEYWORDS}

COVID-19; survey; novel coronavirus; sexual behavior; sexual health; reproductive health; young adults; youth; China

\section{Introduction}

In the past few months, the coronavirus disease (COVID-19) pandemic and related containment measures have caused extensive economic and social damage to many countries like China and the United States [1-3].

From February to April 2020, all schools and many businesses in China were closed. Everyone was required to implement "social distancing," and the government restricted travel, parties, and outdoor activities [4,5]. In addition, many provinces have implemented guidelines to reduce pressure on the health care system, including the suspension of nonemergency medical care and elective surgeries [6]. These disruptions have had a significant impact on the physical and mental health, as well as quality of life, of individuals [7,8].

So far, there is little report about the effects of COVID-19 on sexual and reproductive health $[9,10]$. Sexually active young people are facing more and more health challenges globally $[11,12]$, and various aspects of their reproductive and sexual health may be affected by COVID-19. On the one hand, many young people are facing economic and psychological pressures caused by job loss or suspension of schooling. On the other hand, separation from sexual partners and lack of access to comprehensive health care services may be increasing the risk of experiencing negative sexual health outcomes.

Network-based sexual health risk assessments have been considered acceptable, and internet technology has become a powerful tool to promote health $[13,14]$. To assess the impact of COVID-19 pandemic and related containment measures on partner relationships and sexual and reproductive health, we conducted a series of preliminary analyses using data from an internet-based survey among Chinese youths and young adults.

\section{Methods}

\section{Participant Recruitment}

We conducted a cross-sectional, online survey using Questionnaire Star, an online questionnaire survey platform with 82,000,000 users in China. A 20-item survey (Multimedia Appendix 1) was constructed to assess changes in people's sexual and reproductive health during the COVID-19 pandemic. Between May 1 and 5, 2020, 3500 participants in China received links and emails from WeChat or Weibo (similar to WhatsApp and Twitter, respectively), inviting them to participate in a confidential, 20-minute, online survey about sexual and reproductive health on the Questionnaire Star platform.

\section{Data Collection}

Multiple reminders were sent via messaging software, and the invitation letter stated that the current survey was for participants who were sexually active. Approximately US \$5 was offered as an incentive for participants who completed the questionnaire. Duplicate entries were prevented by restricting users with the same IP (Internet Protocol) address from accessing the survey more than once. A missed answer reminder component prompted participants about unfinished questionnaires in real time, and incomplete questionnaires were not submitted to the system. In addition, participants were unable to submit the questionnaire if their total answering time was less than 3 minutes.

Before entering the online survey system, all participants reviewed and approved the electronic consent page. This research was approved by the Ethics Review Committee of Anhui Medical University for research and publication purposes.

The questionnaire collected data on age, race, education, current financial status, SARS-CoV-2 (severe acute respiratory syndrome coronavirus 2) infection status of participants and those around them, self-rated health, accommodations before and during the pandemic, medical and surgical history of participants and their partners, pregnancy (if female), abortion history, sexual orientation, relationship status (ie, exclusive partnership or not), sexual desire, frequency of sexual intercourse, sexual satisfaction, alcohol consumption before or during sexual activities, frequency of masturbation, frequency of use of pornographic content, proportion of condom use (in sexual encounters), risky sexual behavior, and presence of sexually transmitted infections (STIs). Symptoms were assessed for during the COVID-19 pandemic. Before the questionnaire was distributed, 10 college students and 2 professors participated in a pilot study to verify and modify the contents of the questionnaire.

Participants were included in the current analysis if they were 15-35 years old, live in China, and reported penetrative sex (defined as insertion of penis into vaginal or anal orifices) at least once at any time in the past 6 months $(n=1076)$. Of those invited, 35.7\% ( $\mathrm{n}=1249)$ of individuals completed the survey. Foreigners $(\mathrm{n}=11)$; homosexual or bisexual individuals $(\mathrm{n}=16)$; people, or people with partners, who had COVID-19 $(n=0)$ or had contact with someone with COVID-19 $(n=2)$; and those with systemic diseases $(n=23)$ and other serious conditions that can cause sexual dysfunction $(n=10)$ were excluded since their experiences may differ, and their representation in the sample was small.

Due to the complexity of physiological conditions and interference factors, people with STIs $(n=8)$ and those who were pregnant $(n=25)$ or had undergone a recent abortion $(n=6)$ were also excluded from the sexual health analysis, but the COVID-19-related impact on several aspects of their reproductive health and rights were measured. Participants who were pregnant were asked "Have you experienced any difficulties in obtaining maternal care or delivery services due to COVID-19 or the plans to manage it?". Participants who reported a recent abortion were asked "Have you experienced any difficulties in obtaining abortion or post-abortion care due to COVID-19 or the plans to manage it?". Participants who reported STIs were asked "Have you experienced any difficulties in obtaining medical advice or management due to COVID-19 or the plans to manage it?". All participants who answered "yes" were invited to provide a description of their difficulties. Apart 
from that, all participants were asked to fill in a response to "Have you experienced a shortage of contraceptives during the pandemic?".

\section{Results}

\section{User Statistics}

A total of 967 participants were included in the sexual health analysis. The characteristics of the study participants are shown in Table 1. The mean age was 26.6 (SD 4.86) years (range 16 to 35 years), and $55.9 \%(n=541)$ were male. All participants were Han Chinese. Of the 967 participants, almost half $(n=416$, $43 \%$ ) reported a recent deterioration in their financial situation, and $8 \%(n=75)$ reported a poor state of health.

Table 1. Participants' demographic characteristics (N=967).

\begin{tabular}{|c|c|c|c|c|c|}
\hline Characteristic & Total $(\mathrm{N}=967), \mathrm{n}(\%)$ & Male $(\mathrm{n}=541), \mathrm{n}(\%)$ & Female $(\mathrm{n}=426), \mathrm{n}(\%)$ & $F$ & $P$ value \\
\hline Age (year) & & & & 2.26 & .13 \\
\hline $15-25$ & $389(40)$ & $229(43)$ & $160(36)$ & & \\
\hline $25-35$ & $578(60)$ & $312(57)$ & $266(64)$ & & \\
\hline Education level & & & & 3.10 & .21 \\
\hline College or below & $491(47)$ & $263(45)$ & $228(50)$ & & \\
\hline Bachelor & $405(42)$ & $240(44)$ & $165(40)$ & & \\
\hline Master or above & $71(10)$ & $38(11)$ & $33(10)$ & & \\
\hline Current financial situation & & & & 21.15 & $<.001$ \\
\hline Fine & $221(23)$ & $134(25)$ & $87(20)$ & & \\
\hline Unchanged & $330(34)$ & $151(28)$ & $179(42)$ & & \\
\hline Deteriorated & $416(43)$ & $256(47)$ & $160(38)$ & & \\
\hline Self-rated health & & & & 2.76 & .25 \\
\hline Fine & $282(29)$ & $154(28)$ & $128(30)$ & & \\
\hline General & $610(63)$ & $351(65)$ & $259(61)$ & & \\
\hline Poor & $75(8)$ & $36(7)$ & $39(9)$ & & \\
\hline Accommodation (before pandemic) & & & & 0.51 & .77 \\
\hline Campus dormitory & $416(43)$ & $229(42)$ & $187(44)$ & & \\
\hline House with parents & $348(36)$ & $200(37)$ & $148(35)$ & & \\
\hline House without parents & $203(21)$ & $112(21)$ & $91(21)$ & & \\
\hline Accommodation (during pandemic) & & & & 1.37 & .24 \\
\hline House with parents & $706(73)$ & $403(74)$ & $303(71)$ & & \\
\hline House without parents & $261(27)$ & $138(26)$ & $123(29)$ & & \\
\hline
\end{tabular}

\section{COVID-19-Related Impact on Sexual Health}

COVID-19-related impact on sexual health is summarized in Table 2. In all, 68.8\% $(n=665)$ of students included in the analysis reported that they were currently in an exclusive relationship. There were significant differences in sexual health and outcomes between students in an exclusive relationship compared to those who were not in an exclusive relationship.

Of the 967 participants included in the analysis, 22\% $(n=212)$ reported a decrease in sexual desire, $41 \%(n=396)$ experienced a decrease in the frequency of sex, 20\% $(n=192)$ reported a recent decrease in alcohol consumption before or during sexual activities, and $10 \%(\mathrm{n}=94)$ reported a decrease in risky sexual behavior. In addition, $31 \%(\mathrm{n}=298)$ reported partner relationship deterioration during the pandemic (Table 2). With regard to the frequency of masturbation, $30 \%(n=291)$ of participants reported an increase in masturbation during the pandemic, while $23 \%$ $(n=227)$ reported an increase in the use of pornography.

The logistic regression analysis indicated that accommodations during the pandemic, exclusive relationship status, sexual desire, and sexual satisfaction were closely related to partner relationships (Table 3 ). 
Table 2. Coronavirus disease (COVID-19)-related impact on sexual health (N=967).

\begin{tabular}{|c|c|c|c|c|c|}
\hline Items & Total $(\mathrm{N}=967)$ & $\begin{array}{l}\text { In an exclusive relationship } \\
(\mathrm{n}=665), \mathrm{n}(\%)\end{array}$ & $\begin{array}{l}\text { Not in an exclusive relation- } \\
\operatorname{ship}^{\mathrm{a}}(\mathrm{n}=302), \mathrm{n}(\%)\end{array}$ & $F$ & $P$ value \\
\hline Partner relationship & & & & 40.76 & $<.001$ \\
\hline Fine & $205(21)$ & $133(20)$ & $72(24)$ & & \\
\hline General & $464(48)$ & $285(43)$ & $179(59)$ & & \\
\hline Deteriorated & $298(31)$ & $247(37)$ & $51(17)$ & & \\
\hline Sexual desire & & & & 42.52 & $<.001$ \\
\hline Fine & $126(13)$ & $86(13)$ & $40(13)$ & & \\
\hline General & $629(65)$ & $395(59)$ & $234(77)$ & & \\
\hline Deteriorated & $212(22)$ & $184(28)$ & $28(09)$ & & \\
\hline Sexual frequency & & & & 153.38 & $<.001$ \\
\hline Increased & $223(23)$ & $175(26)$ & $48(16)$ & & \\
\hline Unchanged & $348(36)$ & $304(46)$ & $44(15)$ & & \\
\hline Decreased & $396(41)$ & $186(28)$ & $210(70)$ & & \\
\hline Sexual satisfaction & & & & 33.19 & $<.001$ \\
\hline Increased & $115(12)$ & $54(8)$ & $61(20)$ & & \\
\hline Unchanged & 709 (73) & $498(75)$ & $211(70)$ & & \\
\hline Decreased & $143(15)$ & $113(17)$ & $30(10)$ & & \\
\hline Consumed alcohol before or du & exual activities & & & 132.01 & $<.001$ \\
\hline Increased & $58(6)$ & $44(7)$ & $14(5)$ & & \\
\hline Unchanged & 717 (74) & $555(83)$ & $162(54)$ & & \\
\hline Decreased & $192(20)$ & $66(10)$ & $126(42)$ & & \\
\hline Frequency of masturbation & & & & 21.99 & $<.001$ \\
\hline Increased & $291(30)$ & $189(28)$ & $102(34)$ & & \\
\hline Unchanged & $261(27)$ & $206(31)$ & $55(18)$ & & \\
\hline Decreased & $106(11)$ & $78(12)$ & $28(9)$ & & \\
\hline None & $309(32)$ & $192(29)$ & $117(39)$ & & \\
\hline Frequency of pornography use & & & & 30.71 & $<.001$ \\
\hline Increased & $227(23)$ & $123(19)$ & $104(34)$ & & \\
\hline Unchanged & $330(34)$ & $242(36)$ & $88(29)$ & & \\
\hline Decreased & $115(12)$ & $89(13)$ & $26(9)$ & & \\
\hline None & $295(31)$ & $211(32)$ & $84(28)$ & & \\
\hline Proportion of condom use & & & & 5.25 & .07 \\
\hline Increased & $97(10)$ & $61(9)$ & $36(12)$ & & \\
\hline Unchanged & 735 (76) & $501(75)$ & $234(77)$ & & \\
\hline Decreased & $135(14)$ & $103(16)$ & $32(11)$ & & \\
\hline Risky sexual behaviors & & & & $18.87^{\mathrm{b}}$ & $<.001$ \\
\hline Increased & $4(1)$ & $3(1)$ & $1(1)$ & & \\
\hline Unchanged & $76(8)$ & $55(8)$ & $21(7)$ & & \\
\hline Decreased & 94 (010) & $46(7)$ & $48(16)$ & & \\
\hline None & $793(82)$ & $561(84)$ & $232(77)$ & & \\
\hline
\end{tabular}

${ }^{a}$ Chi-square test was performed between the exclusive relationship group and nonexclusive relationship group.

b The "increased" data were merged with the "unchanged" data. 
Table 3. Risk factors related to partner relationships determined by the logistic regression analysis.

\begin{tabular}{|c|c|c|c|c|}
\hline \multirow[t]{2}{*}{ Variable } & \multirow{2}{*}{$\begin{array}{l}\text { Univariate analysis } \\
P \text { value }\end{array}$} & \multicolumn{3}{|c|}{ Multivariate analysis } \\
\hline & & $\mathrm{OR}^{\mathrm{a}}$ & $P$ value & $95 \% \mathrm{CI}$ \\
\hline Age (year) & .03 & 1.38 & .41 & $1.13-1.80$ \\
\hline Education level & .66 & $-\mathrm{b}$ & - & - \\
\hline Current financial situation & .16 & - & - & - \\
\hline Self-rated health & .02 & 1.85 & .19 & $1.37-2.63$ \\
\hline Accommodations (before pandemic) & .21 & - & - & - \\
\hline Accommodations (during pandemic) & .02 & 0.59 & .046 & $0.30-0.86$ \\
\hline In/not in an exclusive relationship & $<.001$ & 0.44 & $<.001$ & $0.27-0.73$ \\
\hline Sexual desire & .002 & 2.01 & .02 & $1.38-2.97$ \\
\hline Sexual satisfaction & $<.001$ & 1.92 & $<.001$ & $1.54-2.50$ \\
\hline Alcohol consumption before or during sexual activities & .36 & - & - & - \\
\hline Frequency of masturbation & .005 & 0.63 & .21 & $0.46-0.88$ \\
\hline Frequency of pornography use & .29 & - & - & - \\
\hline Proportion of condom use & .52 & - & - & - \\
\hline Risky sexual behaviors & .41 & - & - & - \\
\hline
\end{tabular}

${ }^{\mathrm{a} O R}$ : odds ratio.

${ }^{\mathrm{b}}$ Not applicable.

\section{COVID-19-Related Impact on Reproductive Health}

Participants who reported a recent abortion described difficulties COVID-19-related impact on reproductive health is shown in Figure 1. Nine participants who were pregnant reported having difficulties accessing maternal care or delivery services due to COVID-19 or related measures. These difficulties included shortages in the number of hospital beds available for childbirth, restrictions on the number of people accompanying pregnant women for examination or hospitalization, and failure to receive timely prenatal examination.

primarily with making appointments to see a doctor or for surgeries. Three participants who reported STIs experienced difficulties with medical management, mainly booking a doctor's appointment and accessing medicines such as antibiotics.

In the current study, the proportion of condom usage was unchanged due to COVID-19. However, 8.9\% $(n=86)$ of participants said they had experienced a shortage of contraceptives.

Figure 1. Self-reported coronavirus disease (COVID-19)-related impact among respondents.

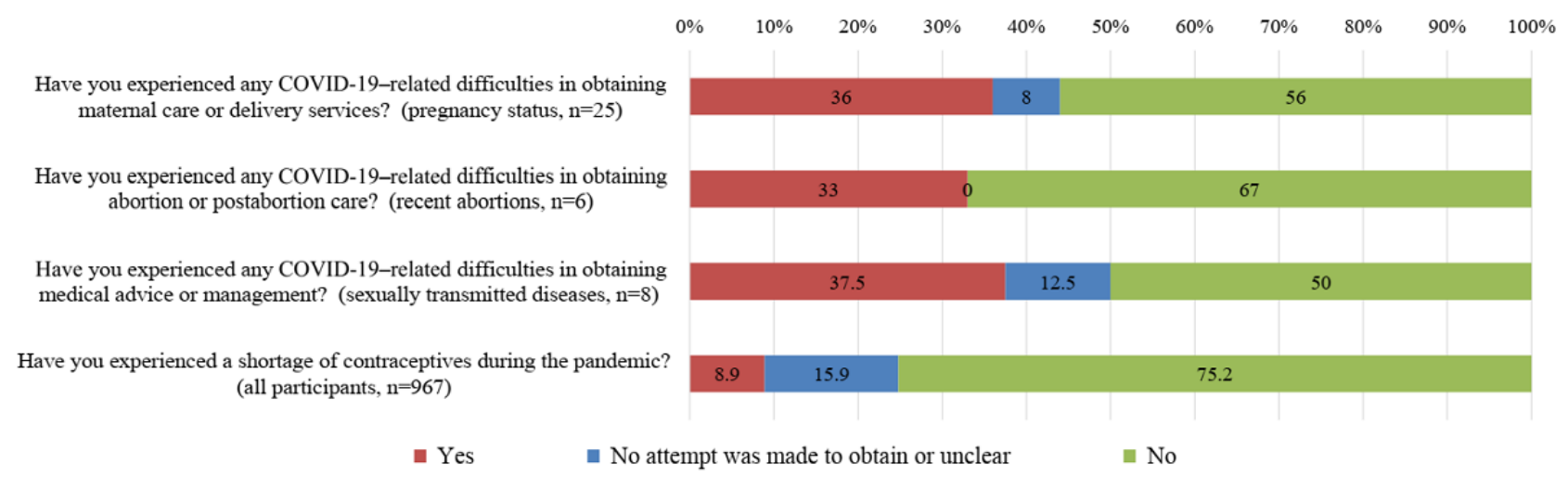

\section{Discussion}

\section{Principal Findings}

Our study provides preliminary evidence on the direct impact of the COVID-19 pandemic and related containment measures on partner relationships and sexual and reproductive health. The results show that many young people had decreased sexual desire and frequency of sexual intercourse due to COVID-19. In addition, a relatively large number of participants reported a significant reduction in alcohol-related sexual consequences and risky sexual behavior. Increased family supervision or interference, less personal freedom overall, and poor mental health and partner relationships are likely contributors to these changes in sexual behavior. 
We found that many participants reported an increase in masturbation frequency and use of pornography. Although masturbation may have helped some people achieve sexual satisfaction without the risk of SARS-CoV-2 infection, a high masturbation rate is related to a decrease in quality of life and sexual satisfaction [15]. High-frequency pornography use may also negatively impact sexual function and quality of life [16].

Our research also provides preliminary evidence of interruptions in reproductive health services due to COVID-19, such as prenatal and postnatal examination, delivery and abortion services, contraception availability, and STI management. In addition, we found that even in a country with a sound drug supply system such as China, contraceptives in some areas were out of stock or in short supply during the pandemic.

\section{Limitations}

The limitations of the current study include the use of a self-designed questionnaire and the reliance upon self-reporting in the midst of the constantly changing prevalence of COVID-19. As a result, our findings are based on cross-sectional data from local convenient samples. In addition, the impact of the COVID-19 pandemic on the sexual health of special groups, including lesbian, gay, bisexual, and transgender people, and people living with HIV, has not been reported in the current research. Further large-scale longitudinal studies are needed to understand the impact of the pandemic on sexual and reproductive health in different regions and populations.

\section{Conclusions}

The COVID-19 pandemic and related containment measures affect young people's sexual health, and targeted interventions are needed to improve health and well-being. In addition, since society is currently focusing on COVID-19 response, basic reproductive health services and supply chain operations have been disrupted. Such services should be protected from disruption and be delivered during the pandemic.

\section{Acknowledgments}

The authors acknowledge all participants and health care providers who participated in this study. This work was supported by the Non-Profit Central Research Institute Fund of the Chinese Academy of Medical Sciences (grant number 2019PT310002).

\section{Conflicts of Interest}

None declared.

\section{Multimedia Appendix 1}

Questionnaire (English version).

[DOCX File, 25 KB-Multimedia Appendix 1]

\section{References}

1. McKee M, Stuckler D. If the world fails to protect the economy, COVID-19 will damage health not just now but also in the future. Nat Med 2020 May;26(5):640-642. [doi: 10.1038/s41591-020-0863-y] [Medline: $\underline{32273610]}$

2. CDC COVID-19 Response Team. Geographic Differences in COVID-19 Cases, Deaths, and Incidence - United States, February 12-April 7, 2020. MMWR Morb Mortal Wkly Rep 2020 Apr 17;69(15):465-471 [FREE Full text] [doi: 10.15585/mmwr.mm6915e4] [Medline: 32298250]

3. Singh RK, Rani M, Bhagavathula AS, Sah R, Rodriguez-Morales AJ, Kalita H, et al. Prediction of the COVID-19 Pandemic for the Top 15 Affected Countries: Advanced Autoregressive Integrated Moving Average (ARIMA) Model. JMIR Public Health Surveill 2020 May 13;6(2):e19115 [FREE Full text] [doi: 10.2196/19115] [Medline: $\underline{32391801]}$

4. Pan A, Liu L, Wang C, Guo H, Hao X, Wang Q, et al. Association of Public Health Interventions With the Epidemiology of the COVID-19 Outbreak in Wuhan, China. JAMA 2020 Apr 10:e [FREE Full text] [doi: 10.1001/jama.2020.6130] [Medline: 32275295]

5. Huang Y, Wu Q, Wang P, Xu Y, Wang L, Zhao Y, et al. Measures Undertaken in China to Avoid COVID-19 Infection: Internet-Based, Cross-Sectional Survey Study. J Med Internet Res 2020 May 12;22(5):e18718 [FREE Full text] [doi: 10.2196/18718] [Medline: $\underline{32396516]}$

6. Schinköthe T, Gabri MR, Mitterer M, Gouveia P, Heinemann V, Harbeck N, et al. A Web- and App-Based Connected Care Solution for COVID-19 In- and Outpatient Care: Qualitative Study and Application Development. JMIR Public Health Surveill 2020 Jun 01;6(2):e19033 [FREE Full text] [doi: 10.2196/19033] [Medline: 32406855]

7. Bavel JJV, Baicker K, Boggio PS, Capraro V, Cichocka A, Cikara M, et al. Using social and behavioural science to support COVID-19 pandemic response. Nat Hum Behav 2020 May 30;4(5):460-471. [doi: 10.1038/s41562-020-0884-z] [Medline: $\underline{32355299]}$

8. Ni MY, Yang L, Leung CMC, Li N, Yao XI, Wang Y, et al. Mental Health, Risk Factors, and Social Media Use During the COVID-19 Epidemic and Cordon Sanitaire Among the Community and Health Professionals in Wuhan, China: Cross-Sectional Survey. JMIR Ment Health 2020 May 12;7(5):e19009 [FREE Full text] [doi: 10.2196/19009] [Medline: 32365044]

9. Yuksel B, Ozgor F. Effect of the COVID-19 pandemic on female sexual behavior. Int J Gynaecol Obstet 2020 Jul 11;150(1):98-102. [doi: 10.1002/ijgo.13193] [Medline: 32392400] 
10. Jacob L, Smith L, Butler L, Barnett Y, Grabovac I, McDermott D, et al. Challenges in the Practice of Sexual Medicine in the Time of COVID-19 in the United Kingdom. J Sex Med 2020 Jul 14;17(7):1229-1236 [FREE Full text] [doi: 10.1016/j.jsxm.2020.05.001] [Medline: 32411271]

11. Tzilos Wernette G, Countryman K, Khatibi K, Riley E, Stephenson R. Love My Body: Pilot Study to Understand Reproductive Health Vulnerabilities in Adolescent Girls. J Med Internet Res 2020 Mar 30;22(3):e16336 [FREE Full text] [doi: 10.2196/16336] [Medline: 32224484]

12. Nielsen A, Bågenholm A, De Costa A. Development of a Mobile Phone App to Promote Safe Sex Practice Among Youth in Stockholm, Sweden: Qualitative Study. JMIR Form Res 2020 Jan 28;4(1):e12917 [FREE Full text] [doi: 10.2196/12917] [Medline: $\underline{\text { 32012038] }}$

13. Tebb KP, Leng Trieu S, Rico R, Renteria R, Rodriguez F, Puffer M. A Mobile Health Contraception Decision Support Intervention for Latina Adolescents: Implementation Evaluation for Use in School-Based Health Centers. JMIR Mhealth Uhealth 2019 Mar 14;7(3):e11163 [FREE Full text] [doi: 10.2196/11163] [Medline: 30869649]

14. Lykens J, Pilloton M, Silva C, Schlamm E, Wilburn K, Pence E. Google for Sexual Relationships: Mixed-Methods Study on Digital Flirting and Online Dating Among Adolescent Youth and Young Adults. JMIR Public Health Surveill 2019 May 16;5(2):e10695 [FREE Full text] [doi: 10.2196/10695] [Medline: 31099335]

15. Brody S, Costa RM. Satisfaction (sexual, life, relationship, and mental health) is associated directly with penile-vaginal intercourse, but inversely with other sexual behavior frequencies. J Sex Med 2009 Jul;6(7):1947-1954. [doi:

10.1111/j.1743-6109.2009.01303.x] [Medline: 19453891]

16. Bőthe B, Tóth-Király I, Potenza MN, Orosz G, Demetrovics Z. High-Frequency Pornography Use May Not Always Be Problematic. J Sex Med 2020 Apr;17(4):793-811 [FREE Full text] [doi: 10.1016/j.jsxm.2020.01.007] [Medline: 32033863]

\author{
Abbreviations \\ COVID-19: coronavirus disease \\ IP: Internet Protocol \\ SARS-CoV-2: severe acute respiratory syndrome coronavirus 2 \\ STI: sexually transmitted infection
}

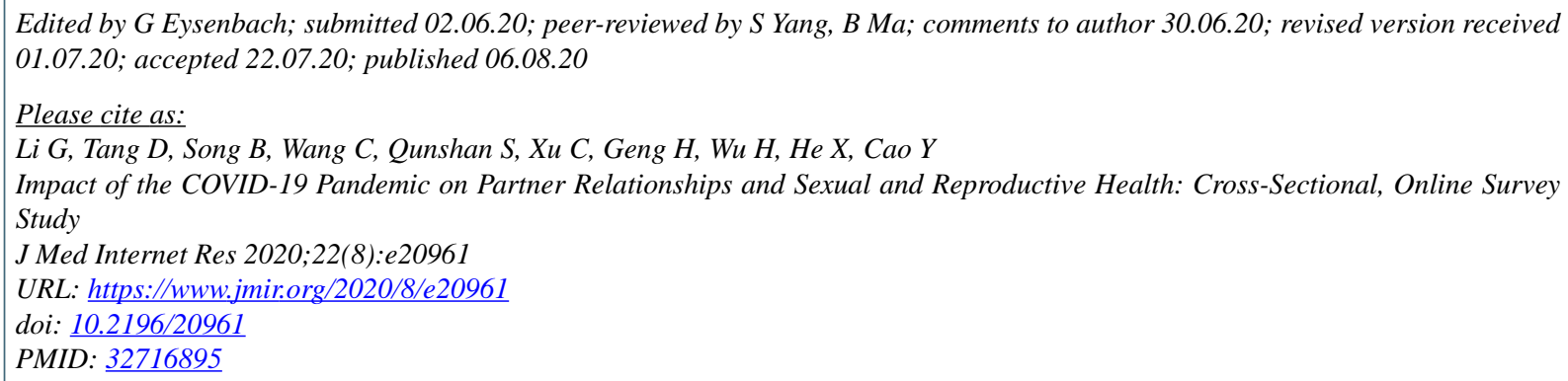

(C) Guanjian Li, Dongdong Tang, Bing Song, Chao Wang, Shen Qunshan, Chuan Xu, Hao Geng, Huan Wu, Xiaojin He, Yunxia Cao. Originally published in the Journal of Medical Internet Research (http://www.jmir.org), 06.08.2020. This is an open-access article distributed under the terms of the Creative Commons Attribution License (https://creativecommons.org/licenses/by/4.0/), which permits unrestricted use, distribution, and reproduction in any medium, provided the original work, first published in the Journal of Medical Internet Research, is properly cited. The complete bibliographic information, a link to the original publication on http://www.jmir.org/, as well as this copyright and license information must be included. 